\title{
HIERARQUIA ENTRE GÊNEROS DE CONVIVÊNCIA NA CONSTITUIÇÃO FEDERAL
}

\author{
Antonio Jorge Pereira Júnior \\ Doutorando em Direito Civil pela Faculdade de \\ Direito da Universidade de São Paulo
}

\begin{abstract}
Resumo:
O trabalho apresenta uma hierarquia sócio-jurídica entre gêneros de convivência constantes da Constituição Federal, que pode ser deduzida a partir da interpretação sistemática dos arts. 226 e 227.
\end{abstract}

\begin{abstract}
:
This work presents a social and juridical hierarchy between companionships genus types, that could be deduced from the systhematic interpretation of the articles 226 e 227.
\end{abstract}

Unitermos: tipos familịares; proteção estatal; hierarquia constitucional

Poder-se-ia demonstrar que um determinado gênero de convivência atende melhor aos interesses da criança e do adolescente ou da sociedade civil? A despeito de um estudo sociológico e/ou psicológico, e de uma análise ideológica do que se entende por "melhor" pode-se cogitar da identificação de uma categoria de relacionamento teoricamente mais apta a atender a "condição peculiar de pessoa em desenvolvimento" ", bem como de satisfazer de modo mais adequado aos interesses da vida social (função social) de acordo com os dispositivos constitucionais. A partir da análise da Constituição Federal e da linha de pensamento sugerida por alguns juristas, pretende-se fazer uma reflexão acerca de uma possível hierarquia entre os tipos familiares concebidos na CF.

O que é a família? Perante a filosofia social, a família é uma sociedade natural, primeira e principal entidade responsável pela formação da pessoa humana. Para o presente estudo interessa analisar, perfunctoriamente, o conceito jurídico de família, bem como sua atual compreensão no Direito Constitucional brasileiro. Com essa breve análise, podem-se identificar, dentre as relações familiares, quais atendem ao melhor interesse da criança e do adolescente.

1. Constituição Federal - doravante $\mathrm{CF}$ - art. $227, \S 3^{\circ}, \mathrm{V}$. 
Não é objeto deste trabalho o estudo vertical do conceito de família, em seu sentido ético, social e jurídico. ${ }^{2}$ Os contornos da instituição familiar serão descritos aqui com a intenção de mostrar que a sociedade civil, por meio da Assembléia Constituinte, impôs ao Estado um modo de gerenciar as situações familiares, dada a importância da primeira e principal sociedade natural - família - para a sociedade civil e para cada pessoa individualmente considerada.

O valor social da familia foi assimilado no topo da hierarquia normativa, por meio do art. 226 da CF "a família, base da sociedade civil, terá especial proteção do Estado". Perante tal afirmação, convém perguntar-se sobre o que se pode entender por familia, neste caso, e que categoria de família constitui base da sociedade civil.

Até meados do século XX se definia a família, habitualmente, como "conjunto de pessoas vinculadas pelo matrimônio ou pelo parentesco (descendência)"” Para efeitos jurídicos, considerava-se família o casal unido matrimonialmente e sua prole. Se nesse quadro desaparecesse um dos cônjuges em virtude de morte, continuaria a união dos filhos com o cônjuge supérstite a ser tida como família, para todos os efeitos.

Durante o século XX, e de modo especial a partir dos anos sessenta, vários fatores levaram a mudanças nessa concepção de família.

Fatores de ordem sócio-econômica, como o aumento de participação do Estado e das organizações privadas na tarefa educativa dos jovens; a desvinculação progressiva do status social do individuo em função do casamento; a consolidação e ampliação da força produtiva das empresas, deslocando para fora do lar o papel econômico que outrora tinha a família, quando era unidade de produção. Restaram à família, basicamente, funções pessoais ou microssociais. ${ }^{4}$

Também os avanços médicos e biológicos influenciaram na estruturação da família: desenvolveram-se meios contraceptivos que lograram separar a sexualidade da reprodução; também se aperfeiçoaram técnicas que levaram, em ordem inversa, a separar a reprodução da sexualidade, mediante a fecundação in vitro.

2. Veja-sc o cstudo de Carlos Alberto BITTAR para maiores detalhes. "Novos rumos do dircito de familia", Direito civil na constituição de 1988 (Coord). São Paulo, 1989, pp.1-37.

3. Hcinrich LEHMANN, Derecho de familia. Tratado de derecho civil, Madrid, Revista de Derecho Privado, 1953, v. 4, p.11.

4. Carlos MARTINEZ DE AGUIRRE, Diagnostico sobre el derecho de familia, Madri, Rialp, 1996, pp. 17-18. O mesmo autor afirma que cm paralclo a csses fatores sócio-cconômicos csquccia-sc que a familia descmpenhava funções formativas c assistenciais de primcira ordem, nas quais ć praticamente insubstituível. 
Nestes dois casos, restando a união sexual dissociada da reprodução, os fins originários do matrimônio vida comum entre esposos, abertura à procriação e educação dos filhos -, puderam ser separados com o auxílio de novas técnicas. As possibilidades oferecidas pela ciência reconfiguraram os hábitos sociais. Em muito isso contribuiu para que nos relacionamentos familiares as pretensões individuais tendessem a sobrepassar eventuais interesses sociais ou supra-individuais que pudessem colidir com elas. O medicamente possivel foi recebido e incorporado por ser ideologicamente desejado. ${ }^{5} \mathrm{O}$ desenvolvimento da medicina cirúrgica, oferecendo a possibilidade de mudar morfologicamente 0 aspecto físico de quem desejava pertencer a sexo diferente daquele com o qual nascera, reforçou a sensação de que estaria ao alcance do poder humano moldar sua realidade morfológica sexual.

Ainda no plano médico, a mortalidade infantil decresceu e a expectativa de vida subiu, afetando a composição dos quadros familiares. A maior parte dos filhos passaram a atingir a idade adulta e os idosos passaram a perdurar por mais tempo na vida familiar e social.

A expansão do trabalho feminino fora do lar contribuiu para mudar a compreensão da família. A mulher ganhou espaço no mercado de trabalho e diminuiu sua dependência econômica com relação ao marido. Somado a outros interesses ideológicos, esse fator levou a uma alteração da estrutura interna da família, onde as funções familiares deixaram de estar vinculadas estritamente à condição sexual do cônjuge, avançando-se na igualdade de poderes e deveres entre os esposos.

Tanto pela desvinculação da maternidade, mediante contraceptivos, quanto pela independência econômica, o casamento passou a se apresentar à mulher como menos necessário. ${ }^{6}$ Neste novo quadro, $o$ aspecto afetivo-sentimental ganhou maior realce, bem como a necessidade de ele estar sendo realimentado em cada época da vida conjugal, para que se preservasse o interesse em manter o vínculo esponsal. $O$ divórcio como possibilidade de desfazimento do vínculo tornou-se uma possibilidade próxima para o caso de enfraquecimento ou ausência do caráter afetivo.

Por fim, fatores de ordem filosófica e ideológica afetaram a visão do matrimônio, da família, e da sexualidade humana.

Perpassando correntes de pensamento que operaram essa metamorfose, pode-se identificar, como pano de fundo comum a todas elas, a idéia de que o matrimônio

5. Carlos MARTINEZ DE AGUIRRE, Diagnostico sobre el derecho de familia, pp.18-21.

6. Carlos MARTINEZ DE AGUIRRE, Diagnostico sobre el derecho de familia, p.23. 
e a família são realidades que não poderiam mais ser indagadas sob uma perspectiva objetiva ou "natural" (direito natural), mas deveriam permanecer como realidades mutáveis e moldáveis em cada época da história humana pela compreensão de cada pessoa ou de cada Estado, sem atributos essenciais perduráveis.

Carlos Martinez de Aguirre aponta como correntes de pensamento que influenciaram essas mudanças de perspectiva: (1) a secularização e o positivismo, que atribuíram à vontade humana e ao Estado o poder de definir o que se deveria entender, e o tratamento que se deveria dar à sexualidade; (2) o individualismo liberal, com a concepção de que o matrimônio e a família são instrumentos a serviço exclusivo dos interesses e satisfações dos indivíduos, sem qualquer finalidade supra-individual; (3) a valorização do aspecto sentimental como razão suprema e fundamento do surgimento e da manutenção do casamento, acima de qualquer outro interesse; (4) o pluralismo ideológico e a neutralidade do Estado frente às diversas concepções acerca do matrimônio, família, sexualidade, e às diferentes formas dos cidadãos organizarem suas relações afetivas e sexuais. ${ }^{?}$

Como resultado desses fatores, a compreensão da família sofreu alterações: ao lado da família matrimonial, no plano sócio-jurídico, veio se instalar a entidade familiar formada pela união estável; ao lado da família formada pelo parentesco (ancestrais comuns), veio se colocar o grupo familiar constituído, originariamente, sob a forma monoparental - mãe ou pai solteiros.

Apesar de maior permissividade, não chegou a vingar no País a disponibilidade absoluta quanto à criação de gêneros de convivência. No texto constitucional percebe-se a força contentora da sociedade politicamente organizada ao reconhecer duas situações como carecedoras de proteção estatal, apontando uma delas como causa exemplar e causa final dentre os gêneros tolerados: entidade familiar (união estável e família monoparental) e família (derivada do matrimônio). Pelos preceitos da Carta Magna nota-se que a concepção de família não depende unicamente da vontade dos indivíduos, sendo legítima a interferência da sociedade e do Estado na relação familiar.

Qual o grau de ingerência do Estado e da sociedade civil nesse âmbito? A título de verificação do grau de interferência do Estado e da sociedade civil na esfera familiar, convém refletir brevemente sobre a normatividade constitucional em matéria de ordem social familiar. 
Nesta análise pode-se perceber que prevalece uma postura individualista de família, constituída sob diversas formas. Todavia, a sociedade civil, representada pela Assembléia Constituinte, ao mesmo tempo em que reconheceu diferentes categorias de organização familiar, estabeleceu entre elas uma hierarquia, apontando quais são socialmente mais adequadas à ordem social.

Além da família matrimonial e da família constituída exclusivamente pela filiação (natural ou jurídica), a CF reconhece a relação informal como "entidade familiar", constituída sem pretensão de vínculo (jurídico) entre homem e mulher (união estável).

Por disposição constitucional, também a familia informal merece "proteção" do Estado. Essa família informal (porque sem forma solene de constituição) é nomeada como espécie de entidade familiar pelo constituinte.

Entidade familiar monoparental

Uma outra espécie de entidade familiar origina-se da relação de filiação, sem a existência prévia de união estável ou de casamento entre os pais. A entidade familiar formada pela comunidade de um dos pais e seus descendentes refere-se, principalmente, às situações de mãe ou pai originariamente solteiros, que vivem com os filhos ${ }^{8}$

Estas situações (mãe ou pai solteiros, com prole) assemelham-se aos casos de famílias constituídas mediante casamento, nas quais um dos cônjuges falece. Seriam praticamente idênticas as situações, não fosse a diferença quanto à origem, que faz que a família matrimonial, enviuvecida e com prole, continue com o status social de família, enquanto a outra não chegaria, socialmente, a ser tratada como tal.

A "proteção" dada à família foi expandida à entidade familiar monoparental.

A ampliação da proteção estatal deve-se, sobretudo, à prioridade absoluta da criança e do adolescente (art. $227 \mathrm{da} \mathrm{CF}$ ), que têm direito de desfrutar dos beneficios jurídicos oriundos da filiação, reservados, em outros tempos, somente aos filhos das famílias constituídas pelo casamento. Parece ser esta a finalidade primordial do reconhecimento e da proteção constitucional da família monoparental.

A família monoparental, portanto, não é um modelo a mais, oferecido aos cidadãos como produto jurídico-familiar apto a satisfazer o interesse de quem deseja

8. A possibilidade do pai soltciro ć real desde que se tomou possível pelo ECA, art. 42, a adoção por pessoas soltciras. 
ter filhos por meio de uma "produção independente". Interpretar a previsão constitucional como incentivo apriorístico a esse tipo de atitude seria contrariar o principio da prioridade absoluta da criança e do adolescente, pois se colocaria a satisfação pessoal de pessoa solteira que deseja ter filhos, acima do direito da criança de desfrutar de um lar completo. É preciso primeiro pensar no melhor interesse da criança.

A adoção unipessoal e o reconhecimento das situações de mães-solteiras são previstas legalmente como meios de solucionar problemas instalados, quando não foi possivel conferir um melhor quadro familiar à criança ou ao adolescente. São remédios que atendem problemas instalados.

É necessário que as autoridades competentes usem de parcimônia ao legislarem ou julgarem a respeito desta matéria, para que se observe, de fato, a prioridade absoluta dos interesses da criança. Caso contrário pode-se favorecer a multiplicação de famílias monoparentais, atendendo ao simples desejo de pessoas adultas solteiras possuírem filhos, sem que se leve em consideração a pessoa do filho, com a dignidade correspondente e a possibilidade real de ter uma família completa.

O planejamento familiar resguardado na Constituição está fundado "nos princípios da dignidade humana e da paternidade responsável", e é "livre decisão do casal' (art. 226, $\S 7^{\mathbf{0}}$; grifos nossos). Ou seja, pressupõe a existência de um casal e deve respeitar a dignidade do "concepturo", que muitas vezes é esquecida... O planejamento familiar não pode ser invocado para lesar, a priori e voluntariamente, $o$ direito que a criança teria de ser educada em uma família completa, de acordo com a ordem natural da vida, ou de saber quem é o seu pai. Por isso é uma temeridade o Direito Positivo e as autoridades públicas permitirem que se instalem, por exemplo, os bancos de esperma ou de embriões. Ao fazer isso está-se tratando a criança como objeto de direito, esquecendo-se de que ela é sujeito, acima de tudo e de todos, e que merece um tratamento diferenciado em função de ser prioridade absoluta: seus direitos fundamentais estão acima dos direitos fundamentais dos pais.

A previsão constitucional da união estável, regulamentada na esfera infraconstitucional, manifesta reação contrária à irresponsabilidade da vida a dois, em face da sociedade civil, pois impede que seja alcançado o desejo de homem e mulher, de conviver à latera de qualquer vinculação jurídica. ${ }^{9}$

9. Deve-sc reconhecer, também, que o reconhecimento da união cstávcl atende, por outro lado, à pretensão legítima do companhciro que pretcndia se casar, mas se vê obrigado a submeter-sc a uma situação informal por cxigĉncia do parcciro. A imposição jurídica do vínculo protege a parte mais fraca na relação. 
A toda liberdade de atuação corresponde uma responsabilidade. Assim, a sociedade civil cobra a responsabilidade correspondente à liberdade de união de homem e mulher que pretendem viver como companheiros, quando desimpedidos de se casarem. Estão exercitando a liberdade em um âmbito que afeta a vida social e, por isso, a sociedade cobra a responsabilidade correspondente ( $\mathrm{CF}$, art. 226).

Os dispositivos constitucionais ora citados, disciplinando a ordem social familiar, parecem confirmar as idéias de Cicu e Maritain: ${ }^{10}$ apesar de a tendência individualista imperar no sistema jurídico pátrio familiar, principalmente desde a edição da lei do divórcio, em 1977, nos dispositivos constitucionais referentes à união estável, vê-se uma reação contrária à subjetivação e individualização" da relação familiar.

Em que medida a família constituída pela convivência marital estável, informal, de um homem e de uma mulher desimpedidos de se casarem, atende interesses da sociedade a ponto de o constituinte prescrever que o Estado proteja essa relação? Somente se justifica isso, quando se reconhece um valor social e jurídico que se sobrepõe ao interesse individual na manutenção e/ou formação da união de ambos. Ou seja, a relação familiar esponsal, seja ou-não matrimonial, tem uma organicidade que transcende seus membros, vinculando-os entre si a despeito do interesse exclusivo dos mesmos em manter-se independentes juridicamente.

$\mathrm{O}$ caráter social do relacionamento durável entre homem e mulher, desimpedidos de se casarem, vivendo como se casados fossem (de acordo com os efeitos sociais principais do casamento), configura o estado social de casados, de modo que efeitos jurídicos se desprendem dessa relação familiar. Essa relação produz efeitos jusfamiliares.

Nestes casos a vontade individual das partes não prevalece sobre a realidade social da vinculação, imposta juridicamente, segundo a compreensão jurídica

10. A partir da Icitura de Antonio CICU ("Il concetto di 'status' ". Studi in onore di Vicenzo Simoncelli. Napoli, Jovenc, 1917, pp. 60-74), temperada pela exposição de Jacques MARITAIN (O homem e o Estado, $4^{a} \mathrm{~cd}$. Rio de Janciro, Agir, 1966), pode-se concluir que a socicdade familiar c a socicdade politica excrecm ccrto poder (orgânico) sobre os scus membros ainda que ambas se constituam em serviço deles.

11. Gustav RADBRUCH, Filosofia do direito, 4"4 cd., Coimbra, Armênio Amado, 1961, pp. 56-69, cntendia como familia individualista aqucla bascada no amor romântico entre cônjuges, na qual cstc amor scria o cixo c justificativa da manutenção do vinculo que unc o casal, tendo cles plena liberdade quanto à criação ou desconstituição dos vínculos. Enquanto isso, a familia supra-individualista scria aquela $\mathrm{cm}$ que há um projeto que transcende csse amor romântico, tendo por finalidade, por cxcmplo, a procriação c cducação da prolc.

Deve-se reconhecer, também, que o reconhecimento da união estável atende, por outro lado, à pretensão Icgitima do companhciro que pretendia sc casar, mas se vê obrigado a submeter-sc a uma situação informal por exigência do parcciro. A imposição jurídica do vinculo protege a parte mais fraca na relação. 
geral, ${ }^{12}$ a despeito da deliberação contrária do companheiro e da companheira. A união estável goza da "proteção do Estado" independentemente da existência de prole, porque se assemelha à união matrimonial. O caráter familiar da união estável serve de fundamento para o reconhecimento impositivo do vínculo e a "formalização" heterônoma da relação, por força da lei (lei da união estável e Código Civil, art. 1.726).

Com o dispositivo constitucional, a sociedade civil uniu juridicamente aqueles que pretendiam manter uma união informal.

A união matrimonial projeta alterações importantes sobre a situação jurídica dos esposos, que passam a ocupar uma função social fundamental na sociedade - passam a integrar a base da sociedade, segundo os termos da Constituição.

União estável e matrimônio

As responsabilidades sociais assumidas pela família matrimonial podem ser reconhecidas nos encargos que essa situação impõe aos cônjuges, que assumem deveres próprios desse novo estado. À autonomia da vontade individual, que serve à constituição da vínculo (contrato), soma-se a responsabilidade socialmente reconhecida (daí o instituto do casamento). A solenidade do matrimônio serve para manifestar esse novo modo de estar dos cônjuges perante a coletividade, com as implicações que traz consigo. ${ }^{13}$

Na união estável é fácil perceber a autonomia da vontade individual na constituição da relação intersubjetiva, sem a formalização do vínculo. No Brasil, a lacuna da formalização voluntária foi preenchida pelo reconhecimento social dessa união, que a partir desse momento mereceu projeção jurídica, importando na alteração do status jurídico dos conviventes. ${ }^{14} \mathrm{~A}$ lei formalizou as uniões duradouras entre homem

12. Antonio JUNQUEIRA DE AZEVEDO cntende que a juridicidade das relações negociais deriva da própria socicdadc, quando o mcio social reconhece o carátcr vinculativo de certas relações, scm a neccssidade da chancela do dircito oficial cstatal. De certa forma isso se opcra, também, nas rclaçõcs familiares: o estado de casado faz que a socicdade tenda a cxigir uma relação jurídica familiar que a fundamentc. (Vide nota 15)

13. Ainda mais cm tcmpos de tão fácil divórcio, não cabc mais o argumento do desuso do casamento pcla indissolubilidadc.

14. O caráter jurídico de uma dada situação decorre principalmente do reconhecimento social desse caráter jurídico por parte da socicdade, restando esse reconhecimento acima da vontade individual das partes c da "vontade cstatal", conforme aponta JUNQUEIRA DE AZEVEDO, Negócio juridico e declaração negocial, Tesc apresentada cm concurso para Professor Titular de Dircito Civil na Faculdade de Dircito da Universidade de São Paulo. São Paulo, 1986, p.11, texto c nota. 
e mulher desimpedidos de casarem, sem considerar as vontades que os companheiros possam ter de manter-se afastados de qualquer vinculação jurídica. Basta, para tanto, que estejam presentes determinados requisitos semelhantes aos exigidos para o casamento.

Há uma função social nos agrupamentos familiares, mesmo naqueles que se constituem de modo imperfeito, como é o caso da união estável, em comparação com o matrimônio. Buscar escapar do compromisso social que a vida familiar ocasiona, pela fuga à formalização do vínculo, seria ludibriar a necessidade da sociedade de reconhecer sua base.

Mas, deve-se notar que apesar de a união estável se assemelhar ao casamento, com ele não se confunde. O constituinte não definiu com idêntico qualificativo as duas situações e previu que a lei facilitasse a conversão da união estável em casamento, o que leva a inferir que o casamento é causa final e causa exemplar da união estável. Além do mais, caso fossem idênticas as situações não haveria porque converter a união estável em casamento. ${ }^{15}$ Nas palavras de Jaques de Camargo Penteado, ${ }^{16}$ amparado na doutrina de Maria Helena Diniz e de Carlos Alberto Bittar: "Os juristas salientam que não houve equiparação entre casamento e união estável. A união estável não gera conseqüencias idênticas às do matrimônio. Salienta-se que a união estável apenas garante a submissão do "par ao denominado Direito Tutelar ou Assistencial." (Bittar).

É sintomático que a Constituição ${ }^{17}$ apresente os conceitos de família e de entidade familiar grafados de modo diferente, em dispositivos autônomos (art. 226, caput e art. $226 \S \S 3^{\circ}$ e $4^{\circ}$ ), que se aproximam apenas "para efeito da proteção do Estado" (art. $226 \S 3^{\circ}$ ). Pode-se concluir da interpretação sistemática do art. 226 e de seus parágrafos que há um modelo, um paradigma ideal de familia desejada pela sociedade: a família matrimonial, como se pode depreender da ordem de apresentação de ambos os conceitos.

15. Traçando uma analogia dos conccitos aristotćlicos de substância c acidentc, Jaques Camargo PENTEADO afirma que familia pode ser entendida como uma substância que se perfaz com notas que vão alćm da cstabilidade, requisito suficiente para a união estávcl. O casamento implica uma rclação perfeita, juridicamente $\mathrm{c}$, por isso, ć a meta final da união cstável. A determinação da conversão da união cstável $\mathrm{cm}$ casamento aponta que há distinção entre ambas c caracteriza o casamento como mais perfcito, pois não faria sentido a CF cncaminhar uma situaçào para outra que fossc pior. A familia e a justiça penal, São Paulo, Rcvista dos Tribunais, 1998, pp.108-109.

16. Jaques de Camargo PENTEADO, A familia e a justiça penal, p.110

17. Convém lembrar que o Estado ć instrumento a scrviço da socicdadc, c a Constillnição ć o instrumento formal do qual se vale o Poder Originário que cria o Estado. 
Primazia hierárquica da família matrimonial

Os $\S \S 1^{\circ} \mathrm{e} 2^{\circ}$ do art. 226 tratam expressamente do casamento, enquanto os $\S \S 3^{\circ} \mathrm{e} 4^{\circ}$ dedicam-se à união estável e à comunidade formada por qualquer dos pais e seus descendentes. Além disso, o art. $226, \S 3^{\circ}$ (que reconhece a união estável como entidade familiar), determina que a lei facilite a conversão da união estável em casamento.

No casamento civil os laços de relacionamento tendem a ser mais fortes. A solenidade do ato e a presença de normas cogentes no contrato de casamento pretendem dar-lhe efeito duradouro e garantir a estabilidade da relação, na medida em que é possivel ao direito. Um quadro de direitos e deveres que estabeleça padrões mínimos de comportamento e de mútuo respeito, e ofereça um modo de gerenciamento do patrimônio familiar, facilita a organização, a convivência e a paz internas no seio familiar, o que convém à sociedade, aos cônjuges e à prole.

Do ponto de vista sócio-jurídico, a formalização expressa melhor a natureza associativa da família pela adesão voluntária a um projeto traçado objetivamente, cujas finalidades e regras básicas de relacionamento estão claramente expressas em lei. Isso confere maior segurança aos que se unem com o objetivo de constituir família, uma vez que passam a ter um estatuto de condutas mínimas que deve ser observado para a manutenção da relação.

A estabilidade jurídica do casal contribui para o beneficio dos filhos. Filhos de pais casados contam com uma referência externa da situação jurídica dos genitores - o modelo matrimonial. Tomando por referência um casal hipotético, unido matrimonialmente, pode-se afirmar que a disciplina jurídica à qual estão submetidos os cônjuges possui contornos precisos, o que facilita a organização da família; se este mesmo casal vivesse em união estável, a relação dos companheiros estaria sob estatuto menos preciso, menos perfeito do ponto de vista jurídico, o que facilita que o relacionamento entre eles mantenha-se mais frágil. Essa fragilidade se reflete também na gestão do poder familiar.

Os deveres decorrentes da filiação, quando somados aos deveres do casamento, tendem a facilitar o trabalho conjunto dos pais perante os filhos. Quanto mais estável o vínculo que os une, em princípio poderão dedicar maior energia na tarefa educativa dos filhos, e os direitos dos filhos serão melhor protegidos. Tal pressuposto parte da perspectiva do direito, obviamente, enquanto organização da vida social. Por isso pode-se afirmar, sob a perspectiva jurídica, que os filhos de pais casados tendem a ter melhores possibilidades de formação. 
Quando não são casados os pais, o Estado deve estar mais atento à formação do menor. "Quando as crianças nascem e os pais estão juntos, não se investiga sobre a capacidade deles, ou seja, o Estado não-interfere para saber se eles estão adequados ou-não".18 O casamento, pela estabilidade jurídica que propicia, é o melhor modelo de união entre homem e mulher na formação da prole.

A extensão da proteção do Estado às entidades familiares responde a uma necessidade: a união estável apresenta uma potencialidade jurígena decorrente do reconhecimento social da similitude dessa situação ao matrimônio: os traços jusfamiliares aí presentes justificam a intervenção protetiva do Estado. À liberdade de "associação familiar" corresponde uma responsabilidade social. Tendo em conta o aspecto jurígeno desses traços, convém que seja encaminhado à forma mais adequada (porque perfeita juridicamente) do casamento (CF, art. $226 \S 3^{\circ}$ e Código Civil, art. 1.726). ${ }^{19} \mathrm{O}$ art. 1.726 do Código Civil, de 2002, regulamenta esta conversão: "a união estável poderá converterse em casamento mediante pedido dos companheiros ao juiz e assento no Registro Civil."

A entidade familiar, portanto, é uma figura que tem por referência a familia matrimonial, em algum de seus traços habituais: pais com prole, na família monoparental, ou, simplesmente, a reunião perdurável de homem e mulher desimpedidos de se casarem.

Diante do exposto, compreende-se porque a associação familiar sofre ingerência externa: está ligada aos interesses e à organização da própria sociedade civil, não podendo ficar à mercê exclusiva das vontades e interesses individuais de quem pretende relacionar-se familiarmente com outra pessoa.

Quando essas associações geram filhos, o grau de interferência externa tende a aumentar, porque a prioridade da criança e do adolescente se impõe a outros interesses individuais. Existindo filiação, haverá poder familiar, e o Estado e a sociedade deverão intervir na administração deste poder, quando se constatar atuação insuficiente ou prejudicial à criança ou adolescente por parte dos responsáveis imediatos. Fora dessas hipóteses, deve-se respeitar a autonomia familiar, pois

"em principio, podemos afirmar que onosso sistema juridico autoriza os pais a criarem seusfilhos da maneira que lhes pareça a mais apropriada. São livres de fazê-lo

18. Tânia da Silva PEREIRA, "O "mclhor" intercsse da criança", O melhor interesse da criança: um debate interdisciplinar. Tânia da Silva PEREIRA (Coord). Rio de Janciro, Rcnovar, 2000 , p.89.

19. Eventualmente poderia se dizer que há aí elementos do suporte fảtico do casamento, mas insuficientes: a conversão $\mathrm{cm}$ casamento completa os clementos faltantes. 
como quiserem. São responsáveis por sua alimentação, vestuário, educação, saúde e lazer. Cabe-lhes definir o parâmetro da educação que pretendem dar, conforme seus próprios modelos e dentro de sua opção cultural ${ }^{\prime 20}$

Visto que o Poder Público interfere na regulação da relação homemmulher, no interesse social que essa união desperta, mesmo na ausência de filhos, quanto mais não deveria fazê-lo na presença deles. Poder-se-ia cogitar, neste caso, da criação de uma curadoria do vínculo (seja ele constituído de modo autônomo ou heterônomo), no interesse dos filhos incapazes por defeito de idade. O curador do vínculo se encarregaria de tentar manter unidos os pais em conflito, buscando-se evitar a dissolução, em função do grau de prejudiciabilidade das separações para a prole, bem como poderia trabalhar para incentivar a conversão da união estável em casamento, para melhor atenção dos filhos e dos interesses da sociedade.

Entre os direitos fundamentais da criança e do adolescente está o direito à convivência familiar, ${ }^{21}$ que é otimizada pela presença de ambos os pais junto ao filho (ECA, art. 19). Há meios modernos de terapia de família que poderiam auxiliar nesse processo. Mas, esta questão não será aqui desenvolvida.

Quando não há laços familiares que fornecem ao incapaz por defeito de idade a atenção conveniente, as demais esferas deverão entrar em ação para tutelar esse indivíduo. A ausência dos pais não faz desaparecer as necessidades decorrentes da "condição peculiar de pessoa em desenvolvimento" (CF, art. 227, § $\left.3^{\circ} \mathrm{V}\right)$.

Para suprir a ausência familiar, a medida mais adequada é a adoção, que busca conferir uma família à criança ou ao adolescente. Quando se opera a adoção, dáse a constituição de um novo título de poder familiar, atribuído aos novos pais, o que não se verifica nas demais situações - guarda ou tutela - em que um título diferente do poder familiar é constituído, atribuindo-se a ele apenas alguns dos poderes inerentes ao poder familiar, sob uma fiscalização mais cerrada do Estado. Em qualquer caso, deve-se buscar que o menor receba o máximo de proteção em qualquer das formas de familia substituta que venha a recebê-lo.

20. Tânia da Silva PEREIRA, "O "mclhor" intcrcssc da criança”, p.48.

21. L. MENDIZÁBAL OSES, Derecho de menores, teoria general, Madrid, Pirâmide, 1977, p.42, argumenta que pelo fato da natureza ter provido todo ser humano naturalmente do bem que ć uma familia, os menores gozariam de uma titularidade dominical sobre tal entidade, que serve para satisfazer suas necessidades primárias c o desenvolvimento de scus interesses essenciais. 
O Estatuto da Criança e do Adolescente, em atenção à prioridade absoluta dos menores, estendeu benefícios próprios da familia natural às familias substitutas ${ }^{22}$ constituídas mediante guarda ou tutela: a guarda oficialmente constituida "confere à criança e ao adolescente a condição de dependente, para todos os fins e efeitos de direito, inclusive previdenciários" (ECA, art. $33 \S 3^{\circ}$ ). A nova relação familiar cumpre a função de suprir a relação familiar originária (no que for possivel suprir), e é justo que se the atribuam os beneficios concebidos para esta, no interesse do menor.

São Paulo, março de 2003.

22. L. MENDIZÁBAL OSES, Derecho de menores, teoria general, pp. 219-229 e seguintes, desenvolve doutrina a respcito do que chamou familia funcional, que se trata de nossa familia substituta constituida mediante guarda c tutcla. 
Bibliografia

BARBOZA, Heloísa Helena. "O estatuto da criança e do adolescente e a disciplina da filiação no Código Civil". O melhor interesse da criança: um debate interdisciplinar. Tânia da Silva PEREIRA (Coord). Rio de Janeiro, Renovar, 2000

BITTAR, Carlos Alberto. "Novos rumos do direito de família”, Direito civil na constituição de 1988 (Coord). São Paulo, 1989, pp.1-37.

CICU, Antonio. "Il concetto di 'status" "Studi in onore di Vicenzo Simoncelli. Napoli, Jovene, 1917, pp.60-74

JUNQUEIRA DE AZEVEDO, Antonio. Negócio jurídico e declaração negocial, Tese apresentada em concurso para Professor Titular de Direito Civil na Faculdade de Direito da Universidade de São Paulo. São Paulo, 1986

LEHMANN, Heinrich. Derecho de familia. Tratado de derecho civil, Madrid, Revista de Derecho Privado, 1953, v.4.

MARITAIN, Jacques. O homem e o Estado, 4a ed, Rio de Janeiro, Agir, 1966

MARTINEZ DE AGUIRRE, Carlos. Diagnostico sobre el derecho de familia, Madrid, Rialp, 1996

MENDIZÁBAL OSES, L. Derecho de menores, teoria general, Madrid, Pirâmide, 1977

PENTEADO, Jaques Camargo. A familia e a justiça penal, São Paulo, Revista dos Tribunais, 1998

PEREIRA, Tânia da Silva. "O "melhor" interesse da criança”, O melhor interesse da criança: um debate interdisciplinar. Tânia da Silva PEREIRA (Coord). Rio de Janeiro, Renovar, 2000

RADBRUCH, Gustav. Filosofia do direito, $4^{\text {a }} \mathrm{ed}$, Coimbra, Armênio Amado, 1961 